\title{
HACIA LA RECUPERACIÓN DE LA SALUD PÚBLICA EN CHILE
}

\author{
Towards the recovery of public health in Chile
}

En la actualidad, con la comprensión de lo que ha ocurrido en Chile en los últimos 40 años y en el contexto de las ideologías y acciones de los actores politicos de todos los sectores y todos los gobiernos, no es posible sostener que en nuestro país existe un sistema mixto o integrado de salud ya que claramente es dual. Toda la evidencia acumulada indica que tenemos dos sistemas, uno público desde la Colonia y reforzado fuerte y constantemente a lo largo del Siglo XIX y especialmente el XX, culminando en 1952 con el Servicio Nacional de Salud. El otro más nuevo, es el privado creado en 1981, rotulado como Instituciones de Salud Previsional (Isapres) aunque se trate, en verdad, de Empresas Privadas de Seguros en Salud. Ambos sistemas obedecen a doctrinas, objetivos, financiamiento y resultados no sólo distintos sino incluso opuestos. El privado se basa en el lucro y evalúa básicamente por prestaciones (número o outputs en inglés), no importando que sean innecesarias siempre que signifiquen ingresos y fundamentalmente por ganancias financieras. Por otra parte, el público mide también las prestaciones, pero siempre por programas de salud y muy desglosadas ya que le interesa fundamentalmente los resultados en salud (impacto o outcomes en inglés), asumiendo responsabilidad por toda la población, incluyendo a los afiliados del sistema privado. Es posible que no le preocupe tanto, como debiera, la satisfacción del usuario aunque no es la norma ni lo más habitual.

Parece innecesario a estas alturas debatir sobre responsabilidades o plantear modificaciones menores, a veces políticas o ideológicas, o simplemente interesadas en relación a lo ocurrido en estos últimos 40 años. Es el rol de los historiadores y también de los salubristas. El objetivo directo de los que trabajamos en el sector público de salud, fundamentalmente médicos y otros profesionales es resolver, a través del diagnóstico y tratamiento, los problemas de las personas que nos consultan con plena confianza en nosotros y en su recuperación, para avanzar en la búsqueda final del bien común, la justicia social, la satisfacción de la población, especialmente la más vulnerable y evaluando siempre por resultados finales. Algunos de estos aspectos se miden con indicadores morales, otros con encuestas o indice de felicidad o con indicadores clásicos de impacto en salud. Esto último, la evaluación de impacto, dada la lógica de mercado que ha sido impuesta e impera hasta la fecha, se ha minimizado o ha estado simplemente ausente, salvo en programas ministeriales acotados.

Lamentablemente, nuestro objetivo como médicos se ha ido contaminando en forma creciente por ideologías y acciones administrativas que han agregado beneficios económicos, alejados con frecuencia de nuestro juramento hipocrático. Lo último relevante en este sentido es, sin duda, la reforma de salud llamada AUGE o acceso universal con garantías explícitas, promulgada el 2004 y poco después calificada como GES, garantías explícitas en salud (probablemente porque, de hecho, no ampara un acceso universal). Es una ley, aunque se trata sólo de un plan de atención médica basado en discriminaciones y una canasta de prestaciones, con cuatro garantías básicas aun no implementadas del todo. Una carencia fundamental del AUGE-GES es no haber incluido indicadores de evaluación de impacto, con un objetivo de salud pública. Lo ocurrido con esta ley se suma al Programa Oportunidad de la Atención de Fonasa (POA, en desarrollo desde 1996, el cual nunca ha evaluado resultados (p. ej. secuela de hernias incisionales) y al Programa de Pago Asociado a Diagnóstico (PAD) de la misma época, también de Fonasa y tampoco evaluado en lo sanitario.

Los promotores del AUGE no se han interesado por su evaluación hasta la fecha, 10 años después de su promulgación, como han reconocido muy recientemente por la prensa. Sin embargo, esa evaluación de impacto ha sido efectuada por médicos clínicos y otros especialistas ya que esta fundamental herramienta de valoración de la atención médica no quedó establecida en la ley AUGE. Las conclusiones de estos investigadores han sido publicadas y son todas negativas. Es interesante destacar que esta ley fue aprobada a pesar de la oposición unánime de todos los colegios profesionales e incluso la opinión contraria de la ministra de salud de la época. Ha significado el traspaso de recursos públicos al sector privado, lo que ha quedado ampliamente ratificado en la práctica hasta la fecha. De hecho, el sector público traspasó al privado sólo en el 2013, la enorme suma de 1.190 millones de dólares, el equivalente a cuatro grandes hospitales modernos. 
En general, lo habitual es que la gente cuando dice o escucha la palabra salud la asocia sólo con atención médica, sin reconocer ni darse cuenta de que salud es bastante más. Existen factores sociales, económicos, psicológicos, demográficos, culturales y muchos otros que a veces son incluso más importantes que la atención de salud, la cual por lo demás no siempre es médica. La calidad de la atención es generalmente buena en ambos sistemas, con mejor hotelería en lo privado. En cuanto a impacto en salud, lo público resulta superior, por mejor costo-efectividad y, por lo tanto, es más eficiente. Hay bastante evidencia al respecto aunque esto no aparezca habitualmente en los medios de comunicación.

Un fenómeno mundial, no sólo de nuestro país, es la relevancia que han alcanzado los economistas en todos los sectores de la sociedad. Por supuesto, una economía sana y creciente es un ideal pero también lo es que la población en su conjunto, toda la sociedad, no sólo partes de ella, goce de bienestar, el cual está influido por ingresos económicos pero también por salud. Una persona o familia de altos ingresos, si no tiene salud, no es nada. A la inversa, si una persona o familia tiene salud pero vive en la pobreza es algo que debe ser corregido. Estas consideraciones no son teóricas, se aplican permanentemente a la realidad, a todas las realidades. La relación entre salud y economía es mutua y recíproca. Lamentablemente, la visión de los economistas se centra más en el mercado y no en lo social.

Si concordamos con las observaciones anteriores y el postulado básico de que en Chile coexisten dos sistemas de salud, diferentes e incluso opuestos pero que no tienen por qué ser enemigos sino simplemente reconocer que transitan por diferentes caminos, deberíamos intentar crear una voluntad colectiva para ser mejores: mejores políticos, mejores personas, mejores médicos, mejores economistas, mejores ciudadanos (as).

En base a las reflexiones entregadas, una larga experiencia administrativa y una visión tanto clínica como de salud pública, creo que se puede proponer con fundamento una serie de acciones que abarcan diversos campos, incluso el constitucional. Deberían servir para acreditar ambos sistemas de salud, los cuales pueden convivir separadamente sin problemas, sin perjuicio de algunos acuerdos convenientes que sirvan para todos (p. ej. diálisis y radioterapias), con el gran objetivo de avanzar hacia un país más sano social y sanitariamente, a la vez que con menores costos.

Las propuestas son las siguientes:

1. Reconocer que las Isapres no son Instituciones de Salud Previsional sino Empresas Privadas de Seguros en Salud (EPSS). En consecuencia, la cotización del 7\% de sus afiliados (establecida por el Estado) debería ir a un Fondo Único de Salud y sus afiliados cotizar directamente de acuerdo al plan que elijan. De hecho, el SNSS estatal es un reaseguro para estas empresas. Además, deben establecerse por ley como sin fines de lucro, igual que las Mutuales de Seguridad.

2. Reintegrar los Consultorios municipalizados a los Servicios de Salud, en forma progresiva. El análisis conjunto de las Interconsultas además de visitas periódicas programadas de los especialistas hospitalarios a la atención primaria serían una gran herramienta para una más rápida y efectiva acción médica en ambos niveles.

3. Evitar al máximo posible y a la brevedad el traspaso de recursos financieros públicos al sector privado (clínicas) por los mecanismos de pago asociado a diagnóstico (PAD desde 1996) y especialmente el AUGE-GES (desde el 2004) para dedicarlos a desarrollar el sector público de salud. Con este objetivo, podrían utilizarse hospitales de emergencia y aplicar programas especiales, como Reducción de Listas de Espera 1991-1994, comprobado como exitoso y otros. El POA debería ser reemplazado por un sistema más justo y solidario, con evaluación de impacto incluida.

4. Se debería acelerar la construcción de nuevos hospitales y mejorar la gestión en los actuales para un mayor rendimiento en calidad y cantidad. Por supuesto, dar término a las concesiones hospitalarias sobre lo cual existe abundante experiencia internacional. Estímulos económicos con participación de los Colegios Profesionales. Mejorar el clima laboral y sentido de pertenencia podría significar el re-encantamiento de los funcionarios, tanto o más necesario que mejor gestión y mayores recursos. Se deben promover estilos participativos de gestión. La carrera funcionaria sería un gran mecanismo en este sentido.

5. Ordenar que el nivel central, Ministerio de Salud con un Departamento de Finanzas, o Fonasa, según se establezca, pague a sus hospitales los costos reales de sus prestaciones. No es posible que en la actualidad se pague un determinado valor a los hospitales públicos y uno mucho más elevado a las clínicas 
privadas por un mismo tipo de prestación. El pago por valores verdaderos evitaría la siempre creciente deuda hospitalaria que tiene relación con esta discriminación y una mayor producción relativa.

6. Solicitar al Gobierno la transformación del actual sistema de Alta Dirección Pública. Debería ser un sistema de verdaderos concursos, públicos y transparentes, despolitizado, entre otros aspectos. Para una buena gestión es muy importante tener buenos directivos además de un estilo participativo que privilegie excelentes comunicaciones.

7. Promover que los hospitales y consultorios de las Mutuales de Seguridad aumenten la atención de usuarios Fonasa con patologías comunes, en base a los aranceles establecidos, con el objeto de reducir la demanda en los hospitales públicos.

8. Solicitar al Tribunal Constitucional su pronunciamiento sobre inconstitucionalidad de la ley AUGE por ser discriminatoria y no cumplir acuerdos internacionales firmados por Chile. En caso adverso, correspondería una modificación de nuestra Carta Fundamental. En el intertanto, se debería revisar y evaluar con epidemiólogos y clínicos especialistas las guías clínicas y el impacto en salud de este plan constituido en ley, tanto en pacientes AUGE como no AUGE, con sus discriminaciones de género, edades de protección, paquetes de prestaciones, centralismo, rigidez, oportunidad, calidad, etc. Esto evitaría el aumento de las sobre 100.000 causas judiciales ya acumuladas.

9. Fortalecer al Ministerio de Salud como ente rector de la salud en el sector público. Lo fundamental en salud es lo sanitario, no lo financiero. Además, la atención médica no lo es todo. Se puede pensar que dada la escasez de economistas sociales, Fonasa debería transformarse en un Departamento de Finanzas del Ministerio.

10. Fomentar la simplificación administrativa en todos los niveles del sector público de salud. Esto se refiere a leyes médicas, carrera funcionaria, incentivos económicos, programas de salud. acciones médicas y todo aquello que ha conducido a su fragmentación. Coordinación con los Colegios Profesionales y Sociedades Cientificas.

11. Establecer que cualquier sistema de control horario de los funcionarios de salud (como señala Contraloría) no excluya la necesaria y conveniente responsabilidad y compromiso de directivos y jefes de servicio, buscando siempre no sólo una hora de entrada y otra de salida, sino fundamentalmente el compromiso y calidad del trabajo.

12. Fortalecer la auditoría, tanto clínica como administrativa. No sólo contar prestaciones sino también establecer y mejorar su calidad con controles locales, en forma participativa y con un sistema informático moderno dirigido no sólo a lo financiero sino fundamentalmente a la salud.

13. Potenciar la integración entre Ministerio de Salud y Universidades, tanto para formar especialistas como para desarrollar investigación.

14. Desarrollar una mejor coordinación del Ministerio de Salud con los otros Ministerios Sociales: Educación, Vivienda, Trabajo y Desarrollo Social para potenciar programas específicos de prevención de enfermedades y promoción de la salud: obesidad, embarazos en adolescentes, adicciones, accidentes y otros. Privilegiar el modelo bio-psico-social y no sólo bio-médico.

Por supuesto, estas propuestas concretas y especificas se entregan para estimular los debates que correspondan, promoviendo siempre que la discusión sea franca y veraz, en todo sentido. Las ideologías son legítimas pero deben ser explicitadas. Existen numerosos intereses creados, personales y de grupos que pueden ser muy válidos pero que deberían analizarse en la forma más transparente posible. Para ser verdaderamente desarrollados no basta con mayores ingresos o un producto interno bruto elevado sino que debemos constituirnos en un país donde predomine la equidad, tengamos un alto nivel de salud, todos nos respetemos y estemos orgullosos de lo que hemos conseguido. Esto es perfectamente posible.

Dr. Iván Serra $C$.

Cirujano y epidemiólogo, Hospital Dr. Sótero del Río.

Profesor Titular de Salud Pública, Universidad de Chile. Departamento de Salud Pública, Consejo Regional Santiago Colegio Médico de Chile. 